\title{
Investigation on Potential Correlation Between the RNA-Binding Protein of Evolutionarily Conserved MEX3 Family and Non-Small-Cell Lung Cancer
}

\section{Ming Zhang}

First Hospital of Jiaxing

Hualiang Zhang

The Second Hospital of Jiaxing

\section{Linfeng Cao}

First Hospital of Jiaxing

Gouxin Hou

First Hospital of Jiaxing

Chao Lu

First Hospital of Jiaxing

\section{Zhixian Fang}

First Hospital of Jiaxing

Xiaodong Lv

First Hospital of Jiaxing

Jingjing Deng ( D Djj910625@163.com )

First Hospital of Jiaxing

\section{Research Article}

Keywords: MEX3 family, potential correlation, non-small-cell lung cancer

Posted Date: September 20th, 2021

DOl: https://doi.org/10.21203/rs.3.rs-800392/v1

License: (1) (1) This work is licensed under a Creative Commons Attribution 4.0 International License. Read Full License 


\section{Abstract \\ Background}

As mRNA binding proteins, MEX3 (muscle excess 3 ) family highlights its unique characteristics and plays an emerging role in post-transcriptionally regulating programmed of biological processes, including tumor cell death and immunological relevance. These have been shown to be involved in various diseases, however, the role of MEX3 in non-small-cell lung cancer (NSCLC) has not been fully elucidated.

\section{Results}

In this study, we found that the sequence or copy number of MEX3 gene did not change significantly, which can explain the stability of malignant tumor development through the COSMIC database. Further, gene expression in NSCLC was examined using the Oncomine ${ }^{T m}$ database, and the prognostic value of each gene was analyzed by Kaplan-Meier analysis. The results showed that overexpressed of MEX3A, MEX3B, MEX3C and MEX3D were associated with significantly lower OS in patients with NSCLC and LUAD, while overexpressed of MEX3D was associated with significantly poorer OS in patients with LUSC. We also applied the Tumor Immune Estimation Resource (TIMER) tool to assess the correlations between distinct MEX3 and the infiltrating immune cell landscape.

\section{Conclusion}

On this subject, we have learned about the complexity and heterogeneity of NSCLC through MEX3. We found that most of MEX3 is highly expressed in NSCLC. High expression indicates a poor prognosis and has a certain immune correlation. Therefore, these conclusions can lay a framework for the prognosis of NSCLC patients and the development of treatment strategies in the future.

\section{Introduction}

RNA-binding proteins (RBPs) are highly species conserved, maintaining the homeostasis of gene expression and regulating almost all RNA post-transcriptional process ${ }^{1-3}$. MEX3 (muscle excess 3 ) is a member of the evolutionarily conserved RBP family, comprised of four human members (MEX3A-D), which encodes different phosphorylated proteins, exhibits different expression patterns in human genome response ${ }^{4,5}$. Each human MEX3 protein has two $\mathrm{K}$ homology $(\mathrm{KH})$ domains bound to RNA, distinguished from other RBPs by a C-terminal RING called the ubiquitin E3 ligase RING (Really Interesting New Gene) domain ${ }^{4,6}$. This particular indicates that the MEX3 proteins play vital role in the balance between self-renewal and differentiation by mediating self-ubiquitination or ubiquitination of target protein and promoting RING-dependent degradation of HLA-A2 (human leukocyte antigen serotype A2) $m R N A^{6,7}$. The ability of MEX3 proteins can not only interact with different RNA sequences, but also diversify the mechanisms enhanced by the RING domain, despite the increasing complexity of regulation, 
so far, little evidence support these redundant ${ }^{8}$. Consistent with the multi-pathway disease presented by cancer and the multiple roles of MEX3 in regulating gene expression, MEX 3 is involved in multiple biological processes in the occurrence and development of cancer ${ }^{9}$. MEX3 mediates cancer cell proliferation, migration, tumor immune escape mechanism, and the transcription level changes in different cancer types ${ }^{10-12}$; according to the tumor type and family members, the expression of MEX 3 is related to the increase or decrease of patient survival rate.

However, there are few studies on the correlation between MEX3 family and lung cancer, and the conclusions are limited. In agreement, here, we draw attention to investigating on large sample of databases to explore MEX3 family expression, prognostic value, and immune-related effects in nonsmall-cell lung cancer(NSCLC),thereby providing further insights into tumor heterogeneity and targeted therapy.

\section{Materials And Methods}

\section{Somatic Mutations of MEX3 in lung cancer.}

We applied COSMIC database ${ }^{13}$ to establish MEX3 somatic mutation entries, a free online authoritative resource that provides information on gene mutations, fusion, genome rearrangement, and human cancers copy number variations. Data for this study are from COSMIC v92 version, with a deadline of February 20, 2021.

\section{EXpression of MEX3 in NSCLC.}

Oncomine ${ }^{\mathrm{TM}} 4.5$ Research Edition ${ }^{14}$ (http://www.oncomine.org/) used for the exploration of MEX3 expression, a web-based database that contains data mining related to cancer microarray, to conduct genome-wide analyses of major cancer types and normal tissues, and to compare transcriptome expression of the data analyzed. It currently contains 715 data sets ( 86,733 samples). In this study, we used the database to determine the mRNA expression of MEX3 in NSCLC and compared the mRNA levels of lung cancer patients and healthy controls, $P=0.05$, fold change value $>1.5$, the top $10 \%$ genes, as the threshold. Data entries from October 2020 to February 2021, and results were drawn with GraphPad Prism 7 software (GraphPad Software, Inc.).

\section{MEX3 prognostic analysis}

Kaplan-Meier plotter ${ }^{15,16}$ were used to assess the prognostic relevance of MEX3 A-D specifically expressed in NSCLC samples. In our study, Affymetrix Identity (Jetset best Probe ${ }^{17}$, as shown in Table I) identified available genes, used median gene expression values to divide patient samples into high and low expression group, $95 \%$ confidence interval $(\mathrm{Cl})$ calculated log-rank $P$ value and hazard ratio $(\mathrm{HR})$, "Array quality control" and "Exclude biased array " were selected to obtain numerical results through 
univariate Cox regression analysis. Finally, the valuable Kaplan-Meier survival curve (OS, Overall survival) was generated according to these parameters.

\section{Immunological correlation of MEX3}

The immune correlation of MEX3 was completed through the Tumor Immune Estimation Resource (TIMER 2.0, timer.comp-genomics.org/), a web server for comprehensive analysis of tumor infiltrating immune cells ${ }^{18}$, including The Cancer Genome Atlas (TCGA) of cancer genome maps from 32 cancer types, a total of 10,897 samples, six subsets of TIIC including B cells, CD4 + T cells, CD8 + T cells, macrophages, neutrophils and dendritic cells were involved ${ }^{19}$. Here, we investigate the significance of MEX3A-D mRNA expression data and invasion of six immune cell types in lung adenocarcinoma (LUAD) and lung squamous cell carcinoma (LUSC).

\section{Results}

Four MEX3 genes were assessed for mutations by COSMIC database. Prior to February 20, 2021, the characteristics of MEX3 in Table II, and the genetic alteration affecting MEX3 in lung cancer samples in Table III. We found that the regulatory mechanism types in tumors, including lung cancer, are mainly missense mutations. Further, in the regulatory mechanism types study of lung cancer, three regulatory mechanism types were found in Fig. 1, Point Mutations, Copy Number Variation (CNV), Gene Expression. While in these regulatory mechanism types, point mutations mainly occurred in $M E X 3 B$, with the highest mutation frequency being $1.06 \%$; $C N V$ was confirmed on $M E X 3 A$, with the highest mutation frequency $1.99 \%$; Gene Expression (Overexpressed) was determined on MEX3A, with the highest frequency $14.03 \%$. No translocations, insertions, deletions, or loss of heterozygosity were identified. In summary, the results indicate that the sequence or copy number of the MEX3 gene has not altered significantly, except for MEX3A overexpression, which revealed that it is stable and not easy to mutate, leading to malignant proliferation of tumor cells. It may explain the development of malignant tumors.

Oncomine $^{\text {TM }}$ database analysis revealed that MEX3 expression in tissues of NSCLC patients compared to normal. The column bar graph in Fig. 2 was derived from the expression of each gene in tumors of different pathological types. The analysis demonstrated that, compared with normal, expression of MEX3 mRNA were significantly overexpressed in different pathological types. It concluded that: MEX3C does not meet the conditions, and other subtypes are overexpressed. MEX $3 \mathrm{~A}^{20}$ can be found in LUAD, LUSC and large cell lung cancer (LCLC), MEX3B ${ }^{20}$ in LCLC and MEX3D ${ }^{21}$ in LUAD. Furthermore, under the same pathological type and different databases, the distinctions in MEX3 expression were summarized in Table IV.

The prognostic value of MEX3 mRNA expression was examined by Kaplan Meier-plotter [Lung Cancer] 2015 version. Firstly, Fig. 3a demonstrated the prognostic effect of MEX3A mRNA expression. Overexpressed of MEX3A had significantly poor prognosis of NSCLC patients $(H R=1.48 ; \mathrm{Cl}, 1.26-1.75 ; \mathrm{P}=$ 2.9E-06), LUAD (HR = 1.74; $\mathrm{Cl}, 1.36-2.22 ; \mathrm{P}=9.9 \mathrm{E}-06)$, but not in $\mathrm{LUSC}(\mathrm{HR}=1.00 ; \mathrm{Cl}, 0.73-1.36 ; \mathrm{P}=0.99)$. Secondly, the effect of MEX3B mRNA expression on prognosis was examined, once again, the survival 
curves of patients with NSCLC, LUAD, and LUSC were described (Fig. 3b). Over- expressed of MEX3B was associated with decreased $\mathrm{OS}$ in all NSCLC $(\mathrm{HR}=1.37 ; \mathrm{Cl}, 1.17-1.62 ; \mathrm{P}=1.4 \mathrm{E}-04)$ and LUAD cases $(\mathrm{HR}=$ $1.32 ; \mathrm{Cl}, 1.04-1.68 ; \mathrm{P}=0.023)$, but not in patients with LUSC (HR=1.05; $\mathrm{Cl}, 0.77-1.42 ; \mathrm{P}=0.78)$. As indicated in Fig. 3c, the prognostic value of MEX3C mRNA expression was analyzed. In all patients with NSCLC (HR $=0.81 ; \mathrm{Cl}, 0.71-0.91 ; \mathrm{P}=7.8 \mathrm{E}-04)$ and LUAD $(\mathrm{HR}=0.50 ; \mathrm{Cl}, 0.39-0.63 ; \mathrm{P}=5.6 \mathrm{E}-09)$, overexpressed was related to lower OS, but not to LUSC (HR=0.87; $\mathrm{Cl}, 0.69-1.11 ; \mathrm{P}=0.26)$. Finally, Fig. $3 d$ demonstrates the prognostic effect of MEX3D mRNA expression. Over-expressed of MEX3D had statistical difference in patients with NSCLC $(H R=1.30 ; C l, 1.14-1.47 ; P=5.2 E-05)$, LUAD $(H R=2.13 ; \mathrm{Cl}$, $1.67-2.72 ; \mathrm{P}=4.5 \mathrm{E}-10)$ and LUSC $(\mathrm{HR}=0.76 ; \mathrm{Cl}, 0.60-0.96 ; \mathrm{P}=0.02)$.

The associations between MEX3 and clinic pathological characteristics in NSCLC patients were explored, also, including Pathological histology, Stage, American Joint Committee on Cancer (AJCC) classification T, Lymph node status (AJCC stage N), Gender, Smoking status and Chemotherapy. Grade, AJCC stage M and Radiotherapy cannot examined because of invalid samples. As demonstrated in Table V, Overexpressed of MEX3A, MEX3B, MEX3C and MEX3D were associated with significantly lower OS in NSCLC and LUAD, while Overexpressed of MEX3D was associated with significantly poorer OS in patients with LUSC. Next, MEX3A, MEX3C and MEX3D overexpressed were identified to significant poorer OS in stage I, while MEX3C also has a consistent prognosis in stage II in Table S1. MEX3A and MEX3B were significantly associated with classification 2,while MEX3A was associated with classification 1 and MEX3B was associated with classification 3ロshown in Table S2.

MEX3A was correlated with 0 lymph node status (Table S3), meanwhile, four MEX3s were correlated with gender (Table S4) in NSCLC patients. For MEX3A, it was significantly associated to smoking, but MEX3C and MEX3D no significant (Table S5). In contrast, MEX3 was not associated to prognosis with or without chemotherapy treatment in NSCLC patients (Table S6).

The relationship between MEX3 and the immune microenvironment of LUAD and LUSC, as well as information of tumor purity were obtained by TIMER 2.0 database. In LUAD, MEX3A was positively correlated with tumor purity and negatively correlated with the level of dendritic cell infiltration. MEX3B was positively correlated with tumor purity, $C D 4+T$ cell and macrophage infiltration level. MEX $3 C$, not only correlated with tumor purity, but also with CD8 $+T$ cells, $C D 4+T$ cells, macrophages, and neutrophils infiltration levels were positively correlated. Finally, we found that MEX3D has statistically related with tumor purity, but positively in CD4 + T cells, macrophages and neutrophils (Fig. 4a). In LUSC, similarly, MEX3A was shown to be positively correlated with tumor purity, B cells, negatively with CD4 + T cells. MEX3B and MEX3C were positively correlated in tumor purity, $C D 8+T$ cells and CD $4+T$ cells. In addition, MEX3D has no signification on tumor purity, but positively correlates with CD4 $+T$ cells and macrophages (Fig. 4b). Here, further, we assessed that overexpressed MEX3 had no statistically significant difference in the survival rate of NSCLC patients, regardless of whether it was 1 year, 3 years or 5 years $(P>0.05)$.

\section{Discussion}


The human MEX3 family is differentially expressed in healthy tissues of different origins ${ }^{9}$, so in the same way, we are interested in understanding how it is expressed in abnormal tissues, particularly in cancer. In the human protein atlas, members of the MEX 3 family are expressed in heterogeneously types of tumors $^{22,23}$. Many evidences indicated that MEX3A promotes cell proliferation and inhibits cell apoptosis bladder cancer ${ }^{24,25}$, gastric cancer ${ }^{26}$, colorectal cancer ${ }^{27}$. Furthermore, increased MEX3A levels are also reported in liver cancer, which were significantly associated with a poor patients' survival ${ }^{28}$. This study revealed that over-expression of MEX3A had significantly poor prognosis of NSCLC and LUAD, but not in LUSC. In addition, increased expression of MEX3A in NSCLC patients is also associated with stage I, classification tumor, lymph node status, and male, whether chemotherapy has little effect on the prognosis. For MEX3B,there are few studies on tumors. It may be a ubiquitination of Runx3(runt-related transcription factor 3 ) and can increase invasion of gastric cancer cells ${ }^{29}$. Our study revealed that high expression of MEX3B mRNA had decreased OS in all NSCLC and LUAD cases. Over-expressed MEX3B was also associated with classification T2 and T3, and gender of NSCLC patients.

Recently, MEX3A and MEX3C proteins have been reported to be negatively correlated posttranslational regulators of several target genes ${ }^{30}$. In colorectal cancer, MEX $3 C$ has been identified as an unstable gene that is frequently lost in $\mathrm{CIN+}$ (cervical intraepithelial neoplasia+) tumors ${ }^{31,32}$, regulating lipid metabolism through JNK(c-Jun N-terminal kinases) pathway in bladder cancer ${ }^{33}$ and breast cancer ${ }^{34}$. Based on these observations, we hypothesized that MEX3C is an important part of influencing metastasis and prognosis in NSCLC. Consistent with our findings, high expression of MEX3C mRNA was associated with poor prognostic OS in NSCLC and LUAD patients. Several study 35,36 demonstrated that MEX3D reverses apoptosis by interacting with au-rich elements (AREs) and enhances the degradation of BCL2 (B-cell lymphoma2) mRNA. Moreover, MEX3D is frequently deleted in various human cancers ${ }^{37}$, can also participate in the modulation by chemotherapy in AML (acute myeloid leukemia) ${ }^{38}$ and overexpression in androgen-independent prostate cancer ${ }^{39}$. In this study, according to Kaplan-Meier analysis, high expression of MEX3D was observed, it was a good prognostic indicator, not only in LUAD and LUSC, but also in all NSCLC.

In immune response, MEX3B can be used as a co-receptor in the innate antiviral response of toll-like receptor $^{40}$. In melanoma ${ }^{41}$, under-expression of MEX $3 \mathrm{~B}$ is associated with antibodies against the programmed cell death 1 (PD-1) receptor, while over-expression can inhibit T cell-mediated tumor elimination. MEX $3 \mathrm{C}$ is involved in the regulation of proteins, degradation and ubiquitination, and it has been identified as a new type of RNA-binding E3 ubiquitin ligase, which is responsible for posttranscriptional regulation ${ }^{42}$. In present study, our results showed that MEX3B and MEX3C expression was positively related to tumor purity, and $C D 8+T$ cell and $C D 4+T$ cell infiltrating levels. While the function of MEX3A and MEX3D in immune responses has not yet been sufficient research evidence. Abundant evidence ${ }^{8,9}$ that, MEX3 proteins have the ability to regulate gene expression in tumor suppression, negative correlation. In the follow-up, we can explore the research of the targeted inhibitor of MEX3 and it could be identified as a marker of immunotherapy detail. 
In summary, from the research results, in the COSMIC database, the sequence or copy number of MEX has no major alterations, which can explain its more copy number in malignant tumors, that is, malignant proliferation. After that, we used the Oncomine ${ }^{\text {TM }}$ database to detect the expression of MEX3 in NSCLC, and Kaplan-Meier analyzed the prognostic value of genes. The results indicated that in NSCLC and LUAD, the lower prognosis of overexpressed MEX3A, MEX3B, MEX3C, and MEX3D was statistically significant, besides, in LUSC, MEX3D is also highly expressed with poor OS. In addition, MEX3B and MEX3C were positively related to tumor purity, of CD8 $+T$ cells and $C D 4+T$ cells infiltrating levels in TIMER.

These data reflect the potential association of MEX3 in non-small cell lung cancer. We found that most of MEX3 is highly expressed in NSCLC. High expression indicates a poor prognosis and has a certain immune correlation. Therefore, these conclusions can lay a framework for the prognosis of NSCLC patients and the development of treatment strategies in the future. But of course, our research needs to be improved and deepened. In the future, we need to further analyze its post-transcriptional regulatory mechanism and immunomodulatory effects, which is currently the focus of tumor immunotherapy direction.

\section{Declarations}

\section{Acknowledgements}

Not applicable.

\section{Availability of data and materials}

The datasets analyzed in the present study are available in the COSMIC database (https://cancer.sanger.ac.uk/cosmic) and Oncomine ${ }^{T M}$ database (https://www.oncomine.org/resource) and the Kaplan Meier-plotter [Lung Cancer] (http://kmplot.com/analysis/index.php? $p=$ service\&cancer=lung) and the TMIER

(http://timer.comp-genomics.org/)

\section{Ethics approval and consent to participate}

Not applicable.

\section{Patient consent for publication}

Not applicable.

\section{Competing interests}

The authors declare that they have no competing interests.

\section{Authors' contributions}


$M Z, H L Z$, JJD were responsible for the design of the study and interpretation of the data. LF C, HX H, ZX $F$ and XD L examined the archives and identified the databases included in the study, and they also have revised critically the manuscript for important intellectual content. All authors contributed to the writing of the manuscript. All authors read and approved the final manuscript.

\section{Funding}

The present study was supported by Key Discipline of Jiaxing Respiratory Medicine Construction Projectgrant 2019-zc-04, Science Technology Project of Jiaxing grants 2020AD30044 and 2021 AD30156, funds from the Jiaxing Key Laboratory of Precision

Treatment for Lung Cancer, and The Early Diagnosisand Comprehensive Treatment of Lung CancerInnovation Team Building Project.

\section{References}

1. Hentze MW, Castello A, Schwarzl T, Preiss T. A brave new world of RNA-binding proteins. Nat Rev Mol Cell Biol. May 2018;19(5):327-341.

2. Pereira B, Billaud M, Almeida R. RNA-Binding Proteins in Cancer: Old Players and New Actors. Trends Cancer. Jul 2017;3(7):506-528.

3. Castello A, Fischer B, Frese CK, et al. Comprehensive Identification of RNA-Binding Domains in Human Cells. Mol Cell. Aug 18 2016;63(4):696-710.

4. Buchet-Poyau K, Courchet J, Le Hir H, et al. Identification and characterization of human Mex-3 proteins, a novel family of evolutionarily conserved RNA-binding proteins differentially localized to processing bodies. Nucleic Acids Res. 2007;35(4):1289-1300.

5. Espel E. The role of the AU-rich elements of mRNAs in controlling translation. Semin Cell Dev Biol. Feb 2005;16(1):59-67.

6. Cano F, Bye H, Duncan LM, et al. The RNA-binding E3 ubiquitin ligase MEX-3C links ubiquitination with MHC-I mRNA degradation. Embo j. Aug 29 2012;31(17):3596-3606.

7. Joazeiro CA, Weissman AM. RING finger proteins: mediators of ubiquitin ligase activity. Cell. Sep 1 2000;102(5):549-552.

8. Pereira B, Le Borgne M, Chartier NT, Billaud M, Almeida R. MEX-3 proteins: recent insights on novel post-transcriptional regulators. Trends Biochem Sci. Oct 2013;38(10):477-479.

9. Jasinski-Bergner S, Steven A, Seliger B. The Role of the RNA-Binding Protein Family MEX-3 in Tumorigenesis. Int J Mol Sci. Jul 23 2020;21(15).

10. Liang J, Li H, Han J, et al. Mex3a interacts with LAMA2 to promote lung adenocarcinoma metastasis via PI3K/AKT pathway. Cell Death Dis. Aug 13 2020;11(8):614.

11. Hu B, Yang XB, Sang XT. Development and Verification of the Hypoxia-Related and ImmuneAssociated Prognosis Signature for Hepatocellular Carcinoma. J Hepatocell Carcinoma. 2020;7:315- 
330.

12. Jia R, Weng Y, Li Z, et al. Bioinformatics Analysis Identifies IL6ST as a Potential Tumor Suppressor Gene for Triple-Negative Breast Cancer. Reprod Sci. Aug 2021;28(8):2331-2341.

13. Forbes SA, Beare D, Gunasekaran P, et al. COSMIC: exploring the world's knowledge of somatic mutations in human cancer. Nucleic Acids Res. Jan 2015;43(Database issue):D805-811.

14. Rhodes DR, Kalyana-Sundaram S, Mahavisno V, et al. Oncomine 3.0: genes, pathways, and networks in a collection of 18,000 cancer gene expression profiles. Neoplasia. Feb 2007;9(2):166-180.

15. Györffy B, Lanczky A, Eklund AC, et al. An online survival analysis tool to rapidly assess the effect of 22,277 genes on breast cancer prognosis using microarray data of 1,809 patients. Breast Cancer Res Treat. Oct 2010;123(3):725-731.

16. Győrffy B, Surowiak P, Budczies J, Lánczky A. Online survival analysis software to assess the prognostic value of biomarkers using transcriptomic data in non-small-cell lung cancer. PLoS One. 2013;8(12):e82241.

17. Li Q, Birkbak NJ, Gyorffy B, Szallasi Z, Eklund AC. Jetset: selecting the optimal microarray probe set to represent a gene. BMC Bioinformatics. Dec 15 2011;12:474.

18. Li T, Fan J, Wang B, et al. TIMER: A Web Server for Comprehensive Analysis of Tumor-Infiltrating Immune Cells. Cancer Res. Nov 1 2017;77(21):e108-e110.

19. Li B, Severson E, Pignon JC, et al. Comprehensive analyses of tumor immunity: implications for cancer immunotherapy. Genome Biol. Aug 22 2016;17(1):174.

20. Hou J, Aerts J, den Hamer B, et al. Gene expression-based classification of non-small cell lung carcinomas and survival prediction. PLoS One. Apr 22 2010;5(4):e10312.

21. Landi MT, Dracheva T, Rotunno $M$, et al. Gene expression signature of cigarette smoking and its role in lung adenocarcinoma development and survival. PLoS One. Feb 20 2008;3(2):e1651.

22. Uhlén M, Fagerberg L, Hallström BM, et al. Proteomics. Tissue-based map of the human proteome. Science. Jan 23 2015;347(6220):1260419.

23. Thul PJ, Åkesson L, Wiking M, et al. A subcellular map of the human proteome. Science. May 26 2017;356(6340).

24. Huang Y, Fang C, Shi JW, Wen Y, Liu D. Identification of hMex-3A and its effect on human bladder cancer cell proliferation. Oncotarget. Sep 22 2017;8(37):61215-61225.

25. Shi JW, Huang Y. Mex3a expression and survival analysis of bladder urothelial carcinoma. Oncotarget. Aug 15 2017;8(33):54764-54774.

26. Jiang $\mathrm{H}$, Zhang X, Luo J, et al. Knockdown of hMex-3A by small RNA interference suppresses cell proliferation and migration in human gastric cancer cells. Mol Med Rep. Sep 2012;6(3):575-580.

27. Chatterji P, Rustgi AK. RNA Binding Proteins in Intestinal Epithelial Biology and Colorectal Cancer. Trends Mol Med. May 2018;24(5):490-506.

28. Yang D, Jiao Y, Li Y, Fang X. Clinical characteristics and prognostic value of MEX3A mRNA in liver cancer. PeerJ. 2020;8:e8252. 
29. Xue M, Chen LY, Wang WJ, et al. HOTAIR induces the ubiquitination of Runx3 by interacting with Mex3b and enhances the invasion of gastric cancer cells. Gastric Cancer. Sep 2018;21(5):756-764.

30. Bufalieri F, Caimano M, Lospinoso Severini L, et al. The RNA-Binding Ubiquitin Ligase MEX3A Affects Glioblastoma Tumorigenesis by Inducing Ubiquitylation and Degradation of RIG-I. Cancers (Basel). Jan 30 2020;12(2).

31. Burrell RA, McClelland SE, Endesfelder D, et al. Replication stress links structural and numerical cancer chromosomal instability. Nature. Feb 28 2013;494(7438):492-496.

32. Ruhl R, Rana S, Kelley K, et al. microRNA-451 a regulates colorectal cancer proliferation in response to radiation. BMC Cancer. May 3 2018;18(1):517.

33. Chao H, Deng L, Xu F, et al. MEX3C regulates lipid metabolism to promote bladder tumorigenesis through JNK pathway. Onco Targets Ther. 2019;12:3285-3294.

34. Zhang J, Zhou YJ, Yu ZH, et al. Identification of core genes and clinical roles in pregnancyassociated breast cancer based on integrated analysis of different microarray profile datasets. Biosci Rep. Jun 28 2019;39(6).

35. Donnini M, Lapucci A, Papucci L, et al. Identification of TINO: a new evolutionarily conserved BCL-2 AU-rich element RNA-binding protein. J Biol Chem. May 7 2004;279(19):20154-20166.

36. Sagata N, Kato TA, Kano SI, et al. Dysregulated gene expressions of MEX3D, FOS and BCL2 in human induced-neuronal (iN) cells from NF1 patients: a pilot study. Sci Rep. Oct 24 2017;7(1):13905.

37. Calin GA, Sevignani $C$, Dumitru CD, et al. Human microRNA genes are frequently located at fragile sites and genomic regions involved in cancers. Proc. Natl. Acad. Sci. U. S. A. Mar 2 2004;101(9):29993004.

38. Mougeot JL, Bahrani-Mougeot FK, Lockhart PB, Brennan MT. Microarray analyses of oral punch biopsies from acute myeloid leukemia (AML) patients treated with chemotherapy. Oral Surg Oral Med Oral Pathol Oral Radiol Endod. Oct 2011;112(4):446-452.

39. Schinke EN, Bii V, Nalla A, et al. A novel approach to identify driver genes involved in androgenindependent prostate cancer. Mol Cancer. May 23 2014;13:120.

40. Yang Y, Wang SY, Huang ZF, et al. The RNA-binding protein Mex3B is a coreceptor of Toll-like receptor 3 in innate antiviral response. Cell Res. Mar 2016;26(3):288-303.

41. Huang L, Malu S, McKenzie JA, et al. The RNA-binding Protein MEX3B Mediates Resistance to Cancer Immunotherapy by Downregulating HLA-A Expression. Clin Cancer Res. Jul 15 2018;24(14):3366-3376.

42. Moududee SA, Jiang Y, Gilbert N, et al. Structural and functional characterization of hMEX-3C Ring finger domain as an E3 ubiquitin ligase. Protein Sci. Sep 2018;27(9):1661-1669.

\section{Tables}

Table I. Affymetrix ID of MEX3 family in the Kaplan-Meier plotter. 


\begin{tabular}{|ll|}
\hline MEX3 & Affymetrix ID (Jetset best probe set) \\
\hline MEX3A & 226346_at \\
\hline MEX3B & 223627_at \\
MEX3C & 218247_s_at \\
MEX3D & 91816_f_at \\
\hline
\end{tabular}

MEX3, muscle excess 3.

Table II. The characteristics of MEX3 family in COSMIC.

\begin{tabular}{|c|c|c|c|c|c|}
\hline & \multirow[t]{2}{*}{$\begin{array}{l}\text { Chromosomal } \\
\text { location }\end{array}$} & \multicolumn{3}{|c|}{$\begin{array}{l}\text { the distribution of mutations across the primary tissue } \\
\text { types }\end{array}$} & \multirow[t]{2}{*}{$\begin{array}{l}\text { Drug } \\
\text { resistance }\end{array}$} \\
\hline & & Point Mutations & $\begin{array}{l}\text { Copy } \\
\text { Number } \\
\text { Variation }\end{array}$ & Gene expression & \\
\hline MEXЗА & $1 q 22$ & $\begin{array}{l}\text { Endometrium } \\
(3.09 \%)\end{array}$ & $\begin{array}{l}\text { Biliary tract } \\
(8.33 \%)\end{array}$ & $\begin{array}{l}\text { Adrenal gland } \\
(30.38 \%)\end{array}$ & None \\
\hline MEXЗВ & $15 q 25.2$ & $\begin{array}{l}\text { Large intestine } \\
(4.08 \%)\end{array}$ & $\begin{array}{l}\text { Skin } \\
(1.02 \%)\end{array}$ & $\begin{array}{l}\text { Urinary tract } \\
(9.06 \%)\end{array}$ & \\
\hline MEXЗС & $18 q 21.1$ & $\begin{array}{l}\text { Central nervous } \\
\text { system }(6.72 \%)\end{array}$ & $\begin{array}{l}\text { Stomach } \\
(3.39 \%)\end{array}$ & None & \\
\hline MEX3D & 19p13.3 & Cervix $(2.45 \%)$ & $\begin{array}{l}\text { Ovary } \\
(1.32 \%)\end{array}$ & $\begin{array}{l}\text { Adrenal gland } \\
\text { (Over-expressed 49.37\%; } \\
\text { Under-expressed 37.97) }\end{array}$ & \\
\hline
\end{tabular}

MEX3, muscle excess 3.

Table III. Genetic alteration affecting MEX3 family in lung cancer samples (COSMIC database) 


\begin{tabular}{|c|c|c|c|c|}
\hline & $\begin{array}{l}\text { Percent of mutated } \\
\text { samples(number) }\end{array}$ & Genetic alteration & Number & $\begin{array}{l}\text { Percentage } \\
(\%)\end{array}$ \\
\hline \multirow[t]{3}{*}{ MEXЗА } & $272 / 38263$ & Ponit Mutations & $16 / 2608$ & 0.61 \\
\hline & & $\begin{array}{l}\text { Copy number } \\
\text { Variation }\end{array}$ & $20 / 1006$ & 1.99 \\
\hline & & Gene Expression & $143 / 1019$ & 14.03 \\
\hline \multirow[t]{3}{*}{ MEX3B } & $379 / 38350$ & Ponit Mutations & $46 / 2609$ & 1.76 \\
\hline & & $\begin{array}{l}\text { Copy number } \\
\text { Variation }\end{array}$ & $1 / 1006$ & 0.10 \\
\hline & & Gene Expression & $55 / 1019$ & 5.40 \\
\hline \multirow[t]{4}{*}{ MEXЗС } & $311 / 38693$ & Ponit Mutations & $29 / 2742$ & 1.06 \\
\hline & & $\begin{array}{l}\text { Copy number } \\
\text { Variation }\end{array}$ & $2 / 1006$ & 0.99 \\
\hline & & Gene & $53 / 1019$ & 5.20 \\
\hline & & $\begin{array}{l}\text { Gene } \\
\text { Expression(under) }\end{array}$ & $21 / 1019$ & 2.06 \\
\hline \multirow[t]{3}{*}{ MEX3D } & $262 / 38693$ & Ponit Mutations & $13 / 2742$ & 0.47 \\
\hline & & $\begin{array}{l}\text { Copy number } \\
\text { Variation }\end{array}$ & $10 / 1006$ & 0.99 \\
\hline & & Gene Expression & $58 / 1019$ & 5.69 \\
\hline
\end{tabular}

MEX3, muscle excess 3.

Table IV. Expression of MEX3 family in different NSCLC pathological types 


\begin{tabular}{|c|c|c|c|c|c|c|}
\hline \multirow[t]{2}{*}{ MEX3 } & \multirow[t]{2}{*}{ Fold change } & \multirow[t]{2}{*}{ Dataset } & \multicolumn{2}{|c|}{ Sample number } & \multirow[t]{2}{*}{ Total } & \multirow[t]{2}{*}{ P-value } \\
\hline & & & Normal & Cancer & & \\
\hline \multicolumn{7}{|c|}{ A, Lung adenocarcinoma vs. normal } \\
\hline MEXЗА & 1.937 & Hou Lung & 65 & 45 & 110 & $9.11 \times 10^{-14}$ \\
\hline MEX3D & 1.649 & Landi Lung & 49 & 58 & 107 & $7.58 \times 10^{-9}$ \\
\hline \multicolumn{7}{|c|}{ B, Squamous cell lung carcinoma vs. normal } \\
\hline MEXЗА & 1.759 & Hou Lung & 65 & 27 & 92 & $3.64 \times 10^{-10}$ \\
\hline \multicolumn{7}{|c|}{ C, Large cell lung carcinoma vs. normal } \\
\hline MEX3A & 3.534 & Hou Lung & 65 & 19 & 84 & $4.17 \times 10^{-7}$ \\
\hline MEX3B & 2.475 & Hou Lung & 65 & 19 & 84 & $1.94 \times 10^{-5}$ \\
\hline
\end{tabular}

MEX3, muscle excess3; NSCLC, not-small-cell lung cancer.

Table V. Correlation of MEX3 with Pathological histology in NSCLC patients.

\begin{tabular}{|c|c|c|c|c|c|}
\hline & Pathology subtype & Case-low & Case-high & $\mathrm{HR}(95 \% \mathrm{Cl})$ & $P$ value \\
\hline \multirow[t]{3}{*}{ MEX3A } & All & 576 & 568 & $1.48(1.26-1.75)$ & $2.9 \mathrm{E}-06$ \\
\hline & LUAD & 339 & 333 & $1.74(1.36-2.22)$ & $9.9 \mathrm{E}-06$ \\
\hline & LUSC & 136 & 135 & $1.00(0.73-1.36)$ & 0.99 \\
\hline \multirow[t]{3}{*}{ MEX3B } & All & 589 & 555 & $1.37(1.17-1.62)$ & $1.4 \mathrm{E}-04$ \\
\hline & LUAD & 340 & 332 & $1.32(1.04-1.68)$ & 0.023 \\
\hline & LUSC & 137 & 134 & $1.05(0.77-1.42)$ & 0.78 \\
\hline \multirow[t]{3}{*}{ MEX3C } & All & 962 & 963 & $0.81(0.71-0.91)$ & $7.8 \mathrm{E}-04$ \\
\hline & LUAD & 360 & 359 & $0.50(0.39-0.63)$ & $5.6 \mathrm{E}-09$ \\
\hline & LUSC & 262 & 262 & $0.87(0.69-1.11)$ & 0.26 \\
\hline \multirow[t]{3}{*}{ MEX3D } & All & 962 & 963 & $1.30(1.14-1.47)$ & $5.2 \mathrm{E}-05$ \\
\hline & LUAD & 361 & 358 & $2.13(1.67-2.72)$ & 4.5E-10 \\
\hline & LUSC & 262 & 262 & $0.76(0.60-0.96)$ & 0.02 \\
\hline
\end{tabular}


Abbreviation: NSCLC, non-small-cell lung cancer; All stands for NSCLC; LUAD, lung adenocarcinoma; LUSC, lung squamous cell carcinomas; HR: hazard ratio; Cl: confidence interval; Cases-low/high: patient number of low/high expression of the corresponding gene.

\section{Figures}

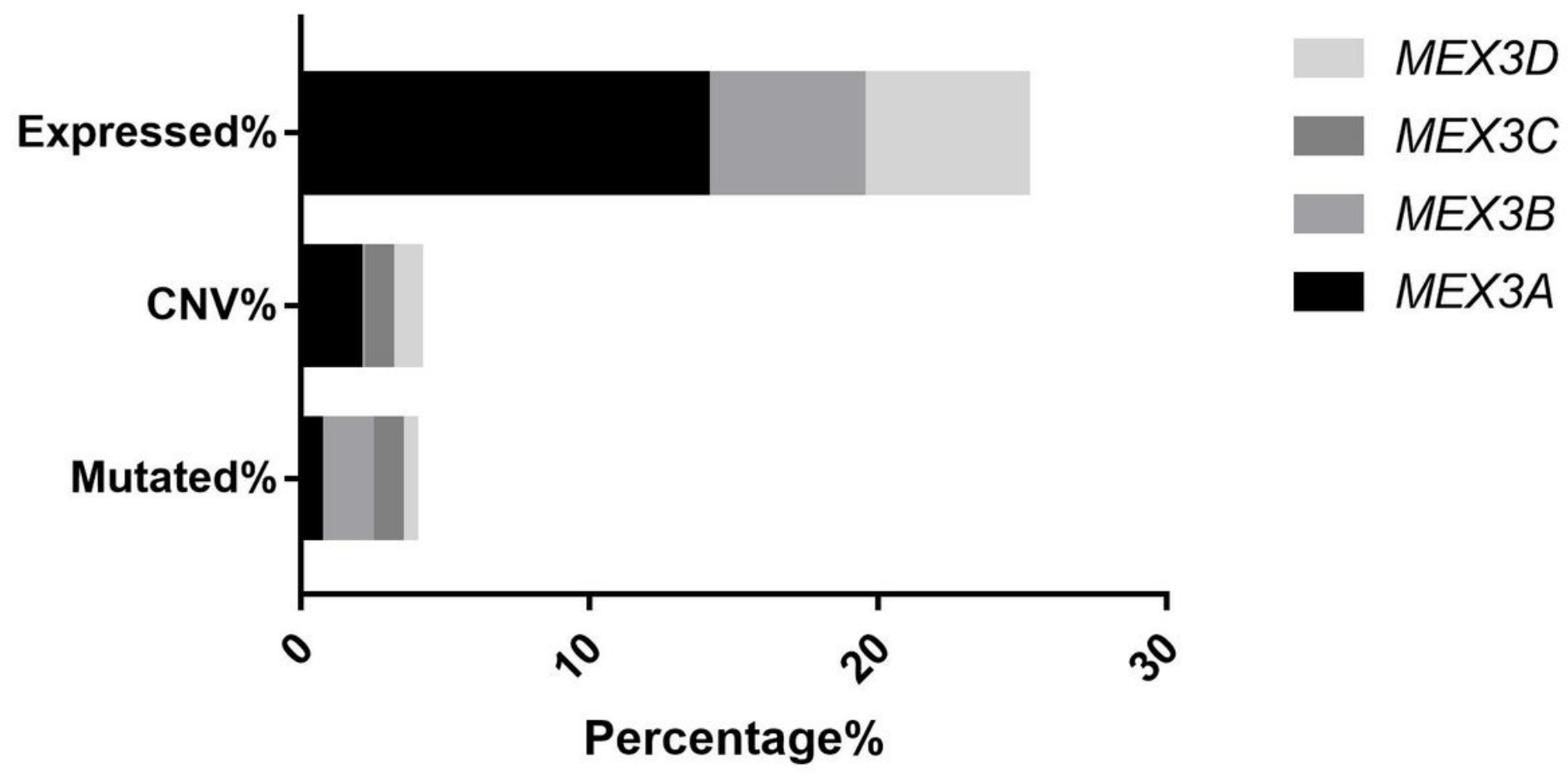

Figure 1

The MEX3 mutation percentage of different mutation types in lung cancer based on COSMIC database. Abbreviation: MEX3, muscle excess $3 \llbracket C N V$, copy number variation. 
MEX3A

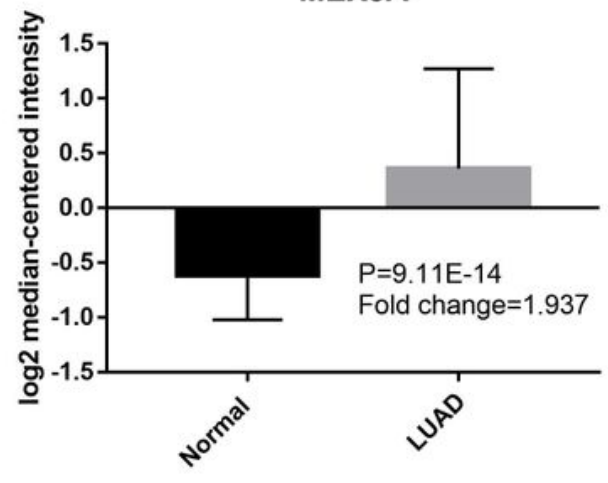

a
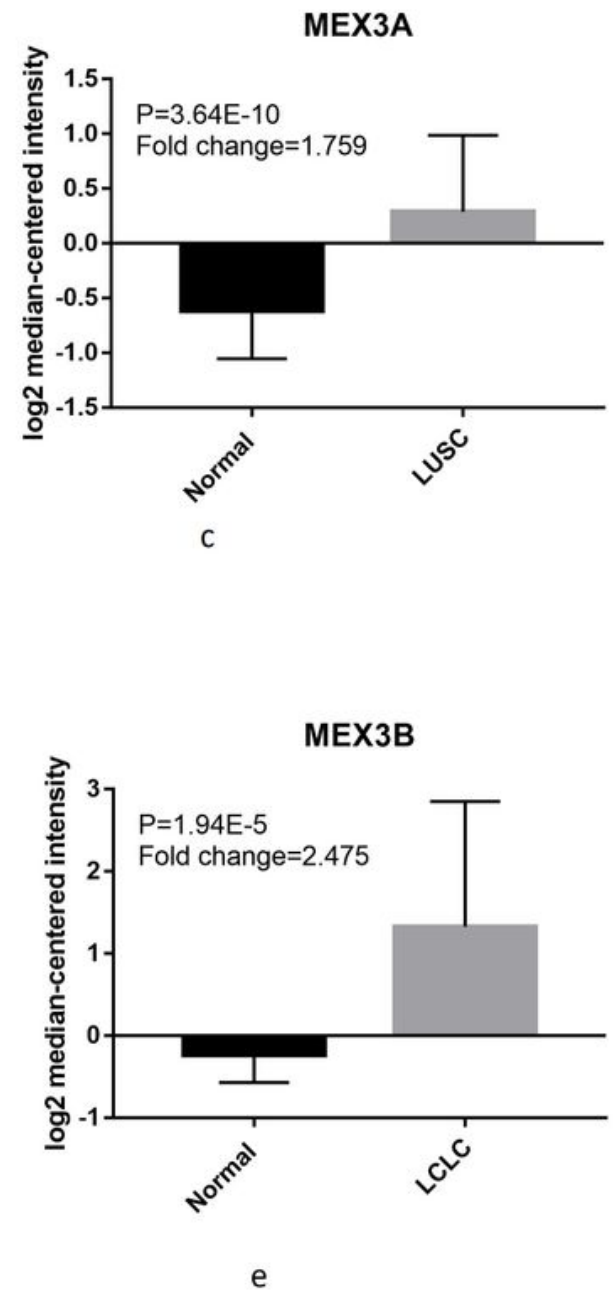

MEX3A

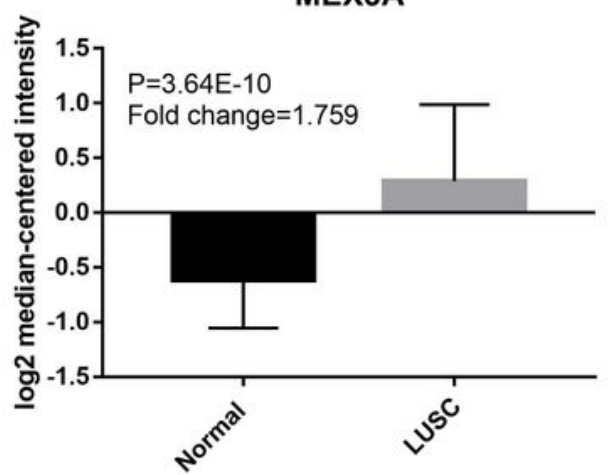

b

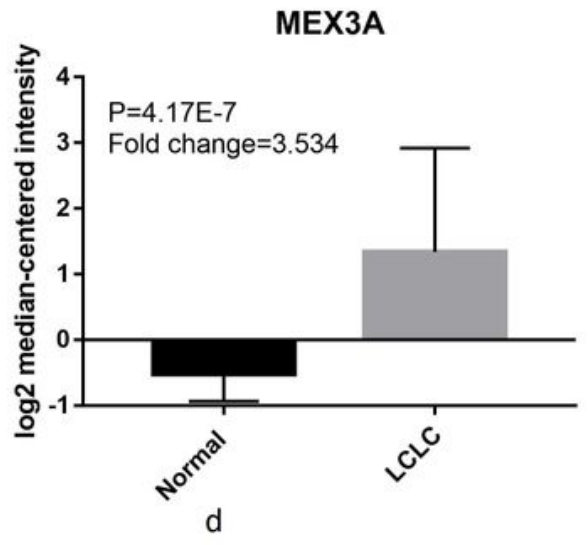

\section{Figure 2}

The analysis of MEX3 in lung cancer from Oncomine analysis. Column bar graph derived from gene expression data in Oncomine comparing expression levels of MEX3 in normal (left plot) and cancer (right plot) tissue and plotted using Graphpad Prism 7 software. Y-axis represents Mean with Standard Deviation (M $\pm S D$ ). (a) Comparison of MEX3A mRNA expression in LUAD. (b) Comparison of MEX3D mRNA expression in LUAD. (c) Comparison of MEX3A mRNA expression in LUSC. (d) Comparison of 
MEX3A mRNA expression in LCLC. (e) Comparison of MEX3B mRNA expression in LCLC. Abbreviation: MEX3, muscle excess 3. Lung adenocarcinoma (LUAD), Lung squamous cell lung carcinoma (LUSC), Large cell lung carcinoma (LCLC).
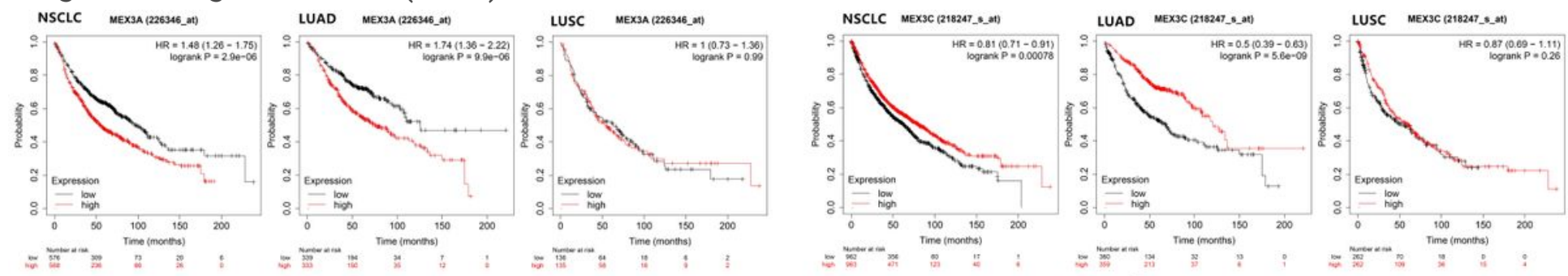

a
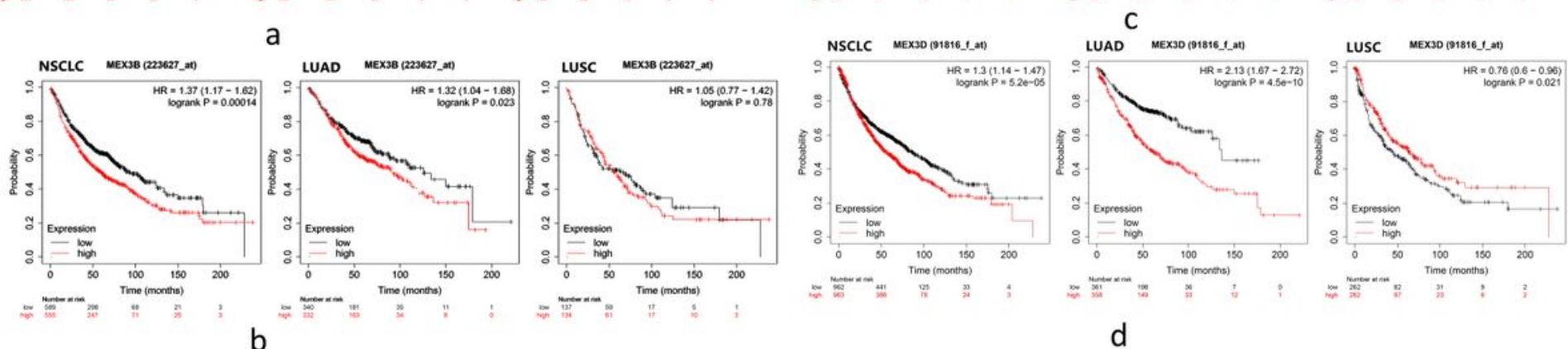

d

\section{Figure 3}

a The prognostic value of MEX3A expression. Survival curves were plotted for all NSCLC patients $(n=1144)$. Survival curves were plotted for LUAD patients $(n=672)$. Survival curves were plotted for LUSC patients $(n=271)$. Data was analyzed using Kaplan-Meier Plotter. Patients with expression above the median are indicated in red line, and patients with expressions below the median in black line. Abbreviation: $\mathrm{HR}$, hazard ratio; $\mathrm{Cl}$, confidence interval. b The prognostic value of MEX3B expression. Survival curves were plotted for all NSCLC patients $(n=1924)$. Survival curves were plotted for LUAD patients $(n=672)$. Survival curves were plotted for LUSC patients $(n=271)$. Data was analyzed using Kaplan-Meier Plotter. Patients with expression above the median are indicated in red line, and patients with expressions below the median in black line. Abbreviation: $\mathrm{HR}$, hazard ratio; $\mathrm{Cl}$, confidence interval. $\mathrm{c}$ The prognostic value of MEX3C expression. Survival curves were plotted for all NSCLC patients $(n=1925)$. Survival curves were plotted for LUAD patients $(n=719)$. Survival curves were plotted for LUSC patients $(n=524)$. Data was analyzed using Kaplan-Meier Plotter. Patients with expression above the median are indicated in red line, and patients with expressions below the median in black line. Abbreviation: HR, hazard ratio; $\mathrm{Cl}$, confidence interval. $d$ The prognostic value of MEX3D expression. Survival curves were plotted for all NSCLC patients $(n=1925)$. Survival curves were plotted for LUAD patients $(n=719)$. Survival curves were plotted for LUSC patients $(n=524)$. Data was analyzed using Kaplan-Meier Plotter. Patients with expression above the median are indicated in red line, and patients with expressions below the median in black line. Abbreviation: $\mathrm{HR}$, hazard ratio; $\mathrm{Cl}$, confidence interval. 

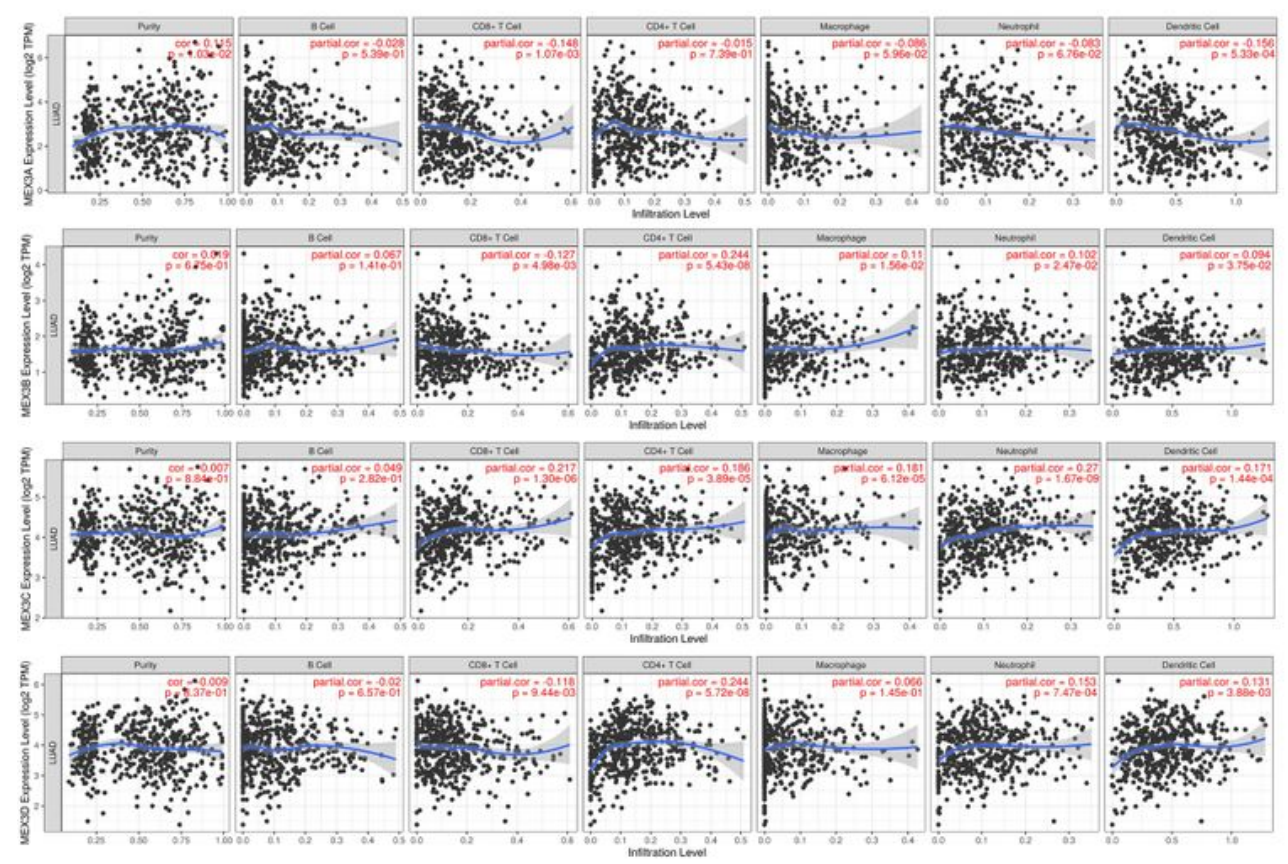

a
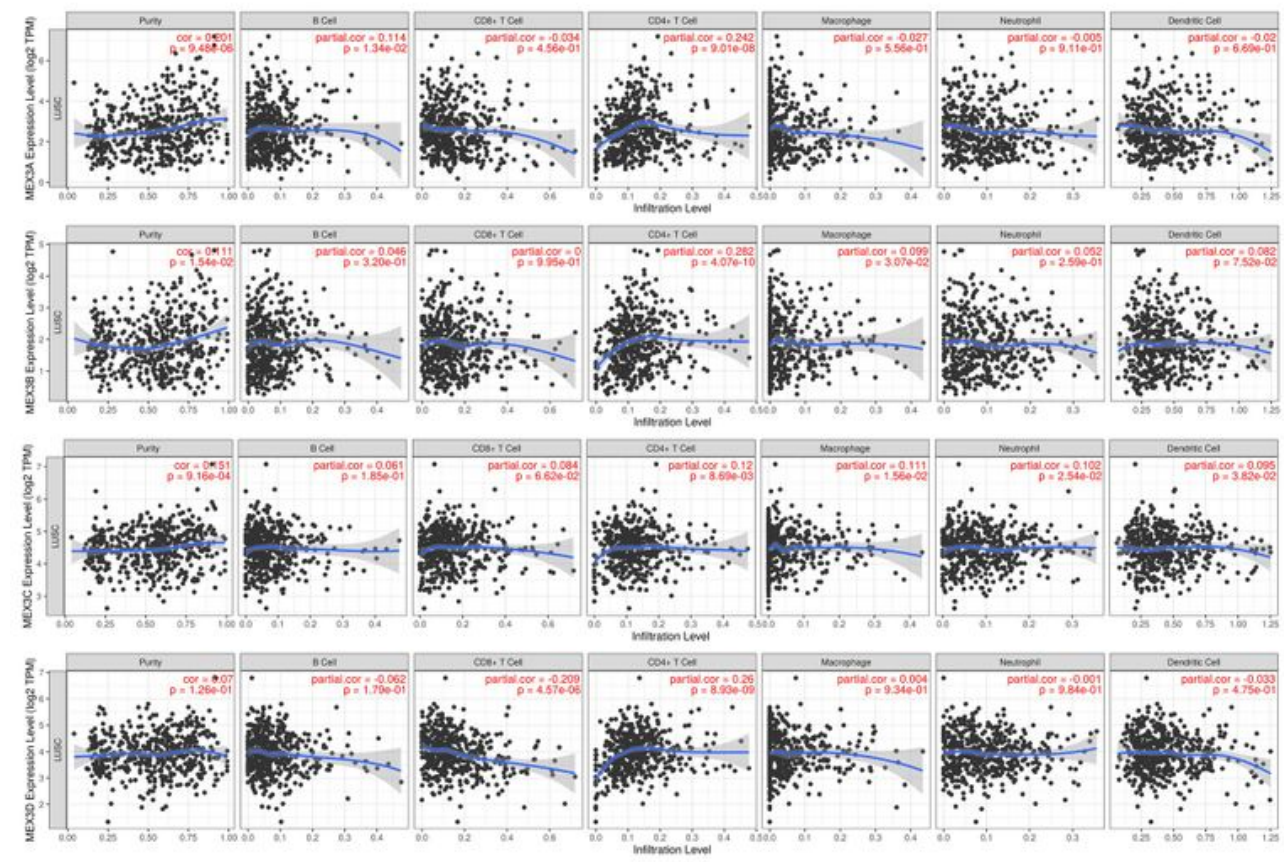

b

\section{Figure 4}

a Correlation between MEX3 and immune cells in LUAD. b Correlation between MEX3 and immune cells in LUSC.

\section{Supplementary Files}


This is a list of supplementary files associated with this preprint. Click to download.

- SupplementalFile.zip 